Sharif University of Technology
Scientia Iranica
SCIENTIA
I RAN I CA

Research Note

\title{
Assessment of urban resilience; a case study of Region 8 of Tehran city, Iran
}

\author{
M. Tabibian ${ }^{\mathrm{a}, *}$ and M. Rezapour ${ }^{\mathrm{b}}$ \\ a. Department of Urban Planning and Design, Fine Arts Faculty, Tehran University, Tehran, Iran. \\ b. Department of Urban Planning and Design, Faculty of Architecture, Qazvin Branch, Islamic Azad University, Qazvin, Iran. \\ Received 26 April 2015; received in revised form 24 July 2015; accepted 5 October 2015
}

\author{
KEYWORDS \\ Resilience; \\ Urban resilience; \\ Urban resilience \\ indicators; \\ Region 8 of Tehran \\ city; \\ Factor analysis.
}

\begin{abstract}
Resilience thinking, its approaches, vocabulary, and metaphors are rapidly becoming part of the terms of urban planning, and evidence of resilience thinking can be found at all levels of decision-making, ranging from transnational to local levels. This paper tries to assess the urban resilience in Region 8 of Tehran city, Iran, without considering any special disaster. Specific attention in the paper is paid to analyzing indicators in assessment of urban resilience to find suitable ones in the case study. After analyzing questionnaires, the rank of urban resiliency was 2.6 , which shows Region 8 of Tehran is in a low position in case of urban resiliency.

(C) 2016 Sharif University of Technology. All rights reserved.
\end{abstract}

\section{Introduction}

Resilience has rapidly become an important urban policy discourse. The emergence of resilience as a driver of urban policy has resulted in a turn towards a more integrated, multi-disciplinary, and open planning system [1]. A simple definition of resilience is the ability of a city to absorb disturbance while maintaining its functions and structures [2]. The study of resilience in relation to planning started in the late 1990s in response to the environmental threats of adjusting social and institutional frameworks. The main focus was on physical and infrastructural improvements to prevent disturbances [3].

This paper aims to assess the urban resilience in Region 8 of Tehran city from the viewpoint of the specialists in related field in order to use it in planning policy-making. In the first step, indicators of assessing resilience were extracted according to different frameworks, dimensions, and indicators of other research

*. Corresponding author. Tel.: +982166414841 E-mail addresses: tabibian@ut.ac.ir (M. Tabibian); mariamrezapour@yahoo.com (M. Rezapour) and they were thoroughly formulated by a group of experts in related fields. So, through a review of the relevant literature, a questionnaire was established. The cultural and socio-economic attributes of Tehran city had been taken into account and eighty interviews were conducted according to face-to-face interviews with experts.

\section{What is resilience?}

Although resilience is a recent addition to the discursive repertoire of planners, it is by no means a new concept. Coming from the Latin root resi-lire, meaning to spring back, resilience was first used by physical scientists. In the 1960s, along with the rise of systems thinking, resilience entered the field of ecology, where multiple meanings of the concept have since emerged with each being rooted in different worldviews and scientific traditions. What set this development in motion was a seminal article published in 1973 by a Canadian theoretical ecologist, Crawford Stanley Holling. In that article, he made a distinction between engineering and ecological resilience [4]. The concept of resilience has often been defined in broad or disparate 
Table 1. Selected definitions of resilience.

\begin{tabular}{|c|c|}
\hline Definition & Source \\
\hline $\begin{array}{l}\text { The persistence of relationships within a system and the ability of these systems to absorb } \\
\text { changes of state variables, driving variables, and parameters and still persist. }\end{array}$ & {$[13]$} \\
\hline $\begin{array}{l}\text { Social resilience is the ability of groups or communities to cope with external stresses } \\
\text { and disturbances as a result of social, political, and environmental change. In other words, } \\
\text { the ability of communities to withstand external shocks to their social infrastructure. }\end{array}$ & [14] \\
\hline $\begin{array}{l}\text { The amount of disturbance a system can absorb and still remain within the same state-the } \\
\text { degree to which the system is capable of self-organization. The degree to which the } \\
\text { system can build and increase the capacity for learning and adaptation. }\end{array}$ & {$[15]$} \\
\hline $\begin{array}{l}\text { The degree to which cities are able to tolerate alteration before reorganizing } \\
\text { around a new set of structures and processes. }\end{array}$ & {$[16]$} \\
\hline $\begin{array}{l}\text { Community seismic resilience is defined as the ability of social units to mitigate hazards, } \\
\text { contain the effects of disasters when they occur, and carry out recovery activities in ways that } \\
\text { minimize social disruption and mitigate the effects of future earthquakes. }\end{array}$ & {$[17]$} \\
\hline The vulnerability of a system to irreversible change. & {$[18]$} \\
\hline $\begin{array}{l}\text { The capacity for adaptation within a system and, in relation to human systems, the ability to } \\
\text { learn and adapt. }\end{array}$ & {$[19]$} \\
\hline $\begin{array}{l}\text { Resilience means the ability of a system, community, or society exposed to hazards to resist, } \\
\text { absorb, accommodate to, and recover from the effects of a hazard in a timely and efficient manner, } \\
\text { including through the preservation and restoration of its essential basic structures and functions. }\end{array}$ & [20] \\
\hline $\begin{array}{l}\text { Resilience in terms of cities generally refers to the ability to absorb, adapt, and respond to changes } \\
\text { in an urban system. }\end{array}$ & {$[5]$} \\
\hline
\end{tabular}

terms depending on the specific application or field of study [5] (Table 1). What is less clear is how resilience can actually be defined, operationalized, or assessed, and whether there are trade-offs and limitations in adopting this approach or not [6].

\section{Urban resilience}

The notions of urban resilience and resilient city have gained considerable attention and interest over recent years, not only in relation to environmental management, but also in terms of urban planning. The notion of urban resilience is not just confined to academic discourses; it is increasingly prevalent in urban policy documents [7]. The rising popularity of urban resilience is fed by growing concerns about urban transformations (whether from rapid growth or shrinking), increasing incidences of natural disasters, and uncertainty about the future (economy, climate change, etc.) [8]. There are some characteristics that show how a city can be more resilient (Table 2). Some of the underpinning barriers to urban resilience planning relate to historical and infrastructural development, geopolitical location, and ecosystem processes such as vulnerability to flooding or earthquake. In addition, some of the social barriers include the capacity of a community to adapt and to influence adaptive processes, local planning policies, institutional structures and organizations, the degree of community capital, and the relative size of an area within the larger entity. There are significant downward stressors, such as power asymmetries, a globalized economy, and demographic change [9]. Increasingly, definitions of resilience include an emphasis on adaptive capacity, which is, for instance, seen as a vital determinant of a resilient city. Adaptive capacity is defined as "the ability to plan, prepare for, facilitate, and implement adaptation options", and determinants include wealth, technology, infrastructure, information, knowledge and skills, commitment to equity, and social capital [10].

\section{Measurement and indicators of resilience}

The gap in the literature is related to measuring resilience and how to assess resilience of a system in general and urban resilience in particular. While 
Table 2. Characteristics of urban resilience (source: [7]).

\begin{tabular}{|c|c|}
\hline Characteristics & Definitions \\
\hline $\begin{array}{l}\text { Attention to the } \\
\text { current situation }\end{array}$ & $\begin{array}{l}\text { Attention to the current situation indicates the ability to understand and maintain } \\
\text { the existing conditions of the environment. It addresses physical facilities and } \\
\text { the monitoring and evaluation of policy. }\end{array}$ \\
\hline $\begin{array}{l}\text { Attention to trends } \\
\text { and future threats }\end{array}$ & $\begin{array}{l}\text { Attention to trends and future threats concerns the ability of prediction on the } \\
\text { basis of current information, for instance, scientific scenarios, models of future impacts, } \\
\text { and the probability of risks in policy-making. This characteristic relates to issues } \\
\text { of trust and learning. }\end{array}$ \\
\hline $\begin{array}{l}\text { Ability to learn from } \\
\text { previous experience }\end{array}$ & $\begin{array}{l}\text { Urban resilience also draws on experiences from the past and requires the capacity } \\
\text { to utilize the necessary knowledge to deal with similar conditions in the future. }\end{array}$ \\
\hline Ability to set goals & $\begin{array}{l}\text { The ability to set goals indicates the willingness (and power) to respond to issues } \\
\text { of changes such as climate change and flood risk management. Visioning } \\
\text { exercises involving multisectoral collaboration may be used to formulate goals. }\end{array}$ \\
\hline $\begin{array}{l}\text { Ability to } \\
\text { initiate actions }\end{array}$ & $\begin{array}{l}\text { The ability to initiate actions is related to the authority of policy-making, } \\
\text { including formal and informal forms of power. These involve different kinds of } \\
\text { resources (e.g., experts, knowledge producers, projects) which allow actions to occur. }\end{array}$ \\
\hline $\begin{array}{l}\text { Ability to } \\
\text { involve the public }\end{array}$ & $\begin{array}{l}\text { The ability to involve the public addresses the degree of public participation in policy } \\
\text { decisions, both in terms of informing the public and response to concerns by the public. }\end{array}$ \\
\hline
\end{tabular}

there is some consensus in the literature on the factors that produce vulnerability to hazards and those that enhance community resilience to disasters, there is less agreement on how to measure them. Because city resilience is a complex, multidisciplinary phenomenon, focusing on a single or small number of contributing factors ultimately results in partial or inaccurate conclusions and misrepresentation of the multiple causes of the phenomenon [11].

By necessity, indicators are generalizations and never completely represent all facets of resilience [6]. Instead, they are approximations that can be used to set policy goals and measure progress towards them; or they can be considered as screening tools to set baselines through mapping distributions and assessing temporal and spatial changes [12].

The major theoretical challenge regarding urban resilience, with which many scholars are faced today, appears to be the development of a multidisciplinary theory that integrates a variety of urban dimensions such as social, economic, cultural, environmental, spatial, and physical infrastructure into a unified conceptual framework for understanding the resiliency of cities and how they should move towards a more resilient state [11] (Figure 1). The availability of indicators, however, varies significantly by dimension (Table 3).

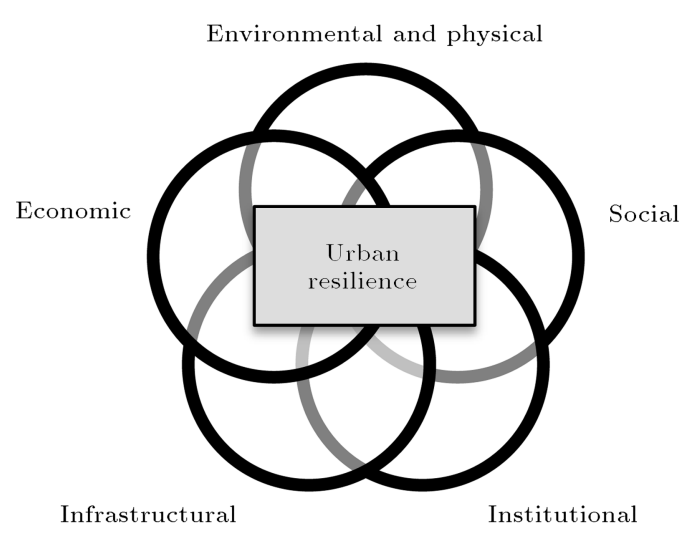

Figure 1. Dimensions of urban resilience.

\section{Methodology}

\subsection{Conceptual model}

According to the theoretical framework, a Conceptual Model is designed which involves hypotheses of the paper (Figure 2); The hypotheses are as follows:

- H1: There is a direct positive relationship between social condition and city resilience;

- H2: There is a direct positive relationship between economic condition and city resilience;

- H3: There is a direct positive relationship between environmental condition and city resilience; 
Table 3. Dimensions and characters of assessing resilience.

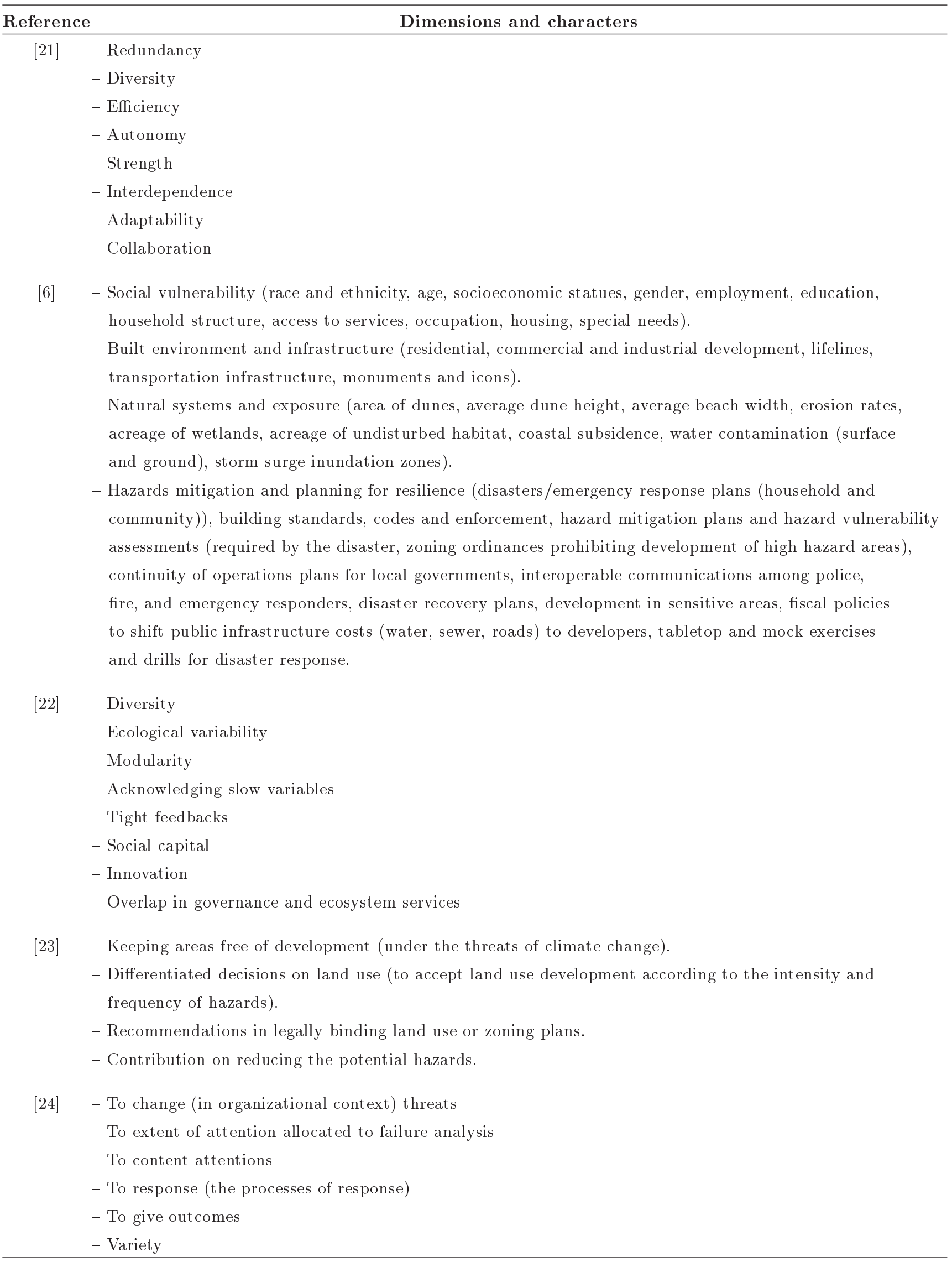




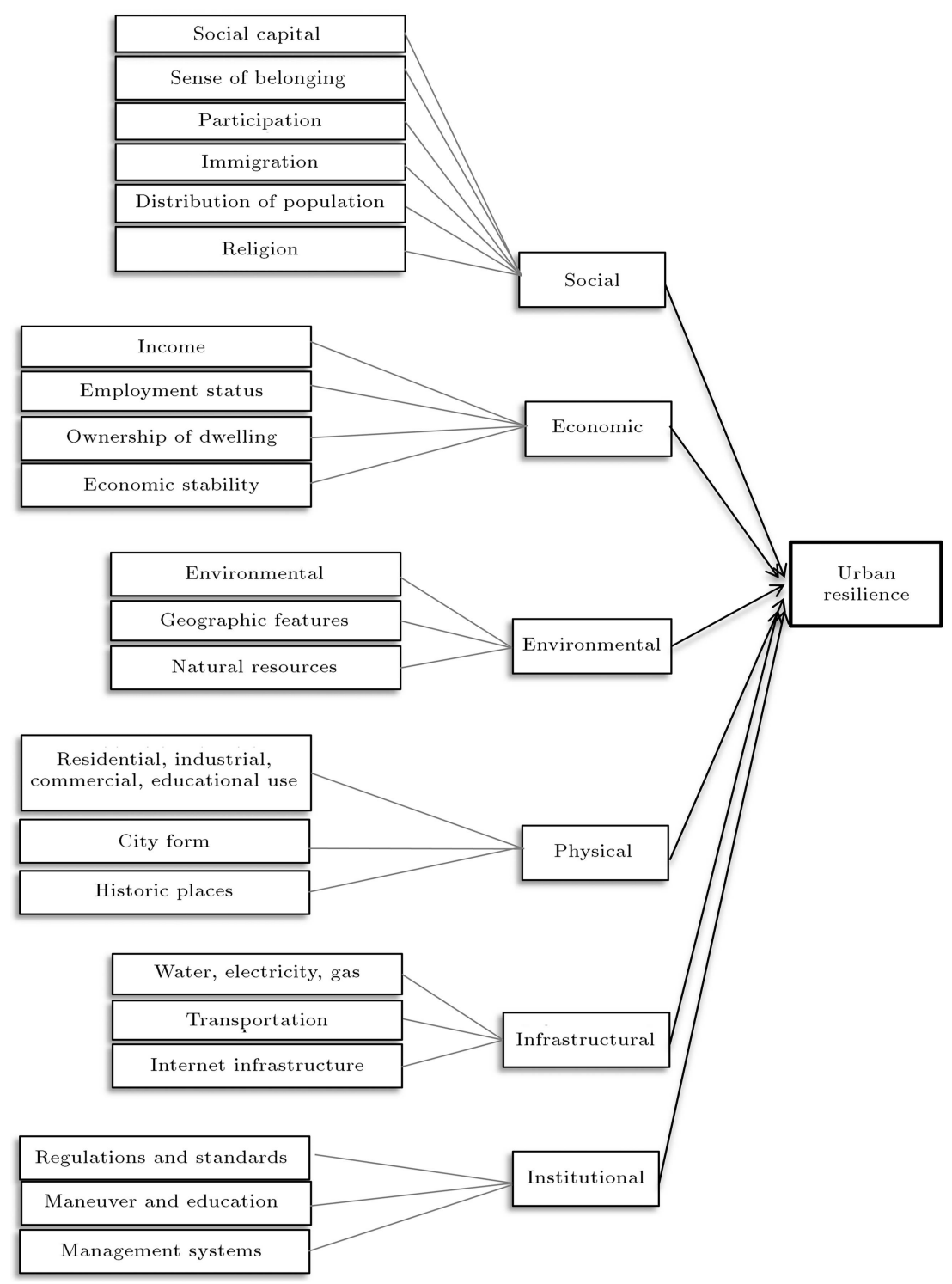

Figure 2. Conceptual model for assessing urban resilience.

- H4: There is a direct positive relationship between physical condition and city resilience;

- H5: There is a direct positive relationship between urban infrastructure and city resilience;

- H6: There is a direct positive relationship between institutional capacity and city resilience.

\subsection{Region 8 of Tehran city as the case study} Region 8 is a predominantly middle-class residential region in Tehran city (Figure 3 ). If earthquake of Rey fault occurs, damage in this region will be great.

\subsection{Questionnaire}

This paper aims to assess the urban resilience in order to use it in planning policy-making in Region 8 of Tehran city from the viewpoint of the specialist in this filed. Through a review of the relevant literature, a questionnaire was established. The cultural and socio-

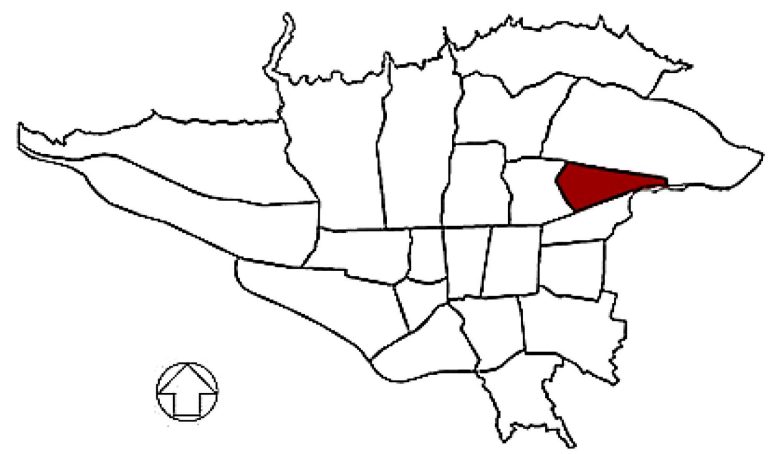

Figure 3. Region 8 of Tehran as the case study.

economic attributes of Tehran city had been taken into account. Before finalizing the questionnaire, it was thoroughly examined by a group of experts in related fields. Eighty interviews were conducted according to face-to-face interviews with experts of municipality of 
Table 4. Indicators of assessing resiliency in Region 8 of Tehran.

\begin{tabular}{ll}
\hline Dimension & \multicolumn{1}{c}{ Indicator } \\
\hline Social & Social capital, sense of belonging, participation, immigration, distribution of population, religion \\
Economic & Income, employment status, ownership of dwelling, economic stability \\
Environmental & Environmental sustainability, geographic features, natural recourses \\
Physical & Residential use, industrial use, commercial use, educational use, city form, historic places \\
Infrastructural & Water, electricity, gas, transportation, internet infrastructure \\
Institutional & Regulations and standards, maneuver and education, management systems \\
\hline
\end{tabular}

Table 5. Regression analysis of dimensions of resilience in Region 8 of Tehran (source: Statistical analysis).

\begin{tabular}{cccccl}
\hline Sig. & $\boldsymbol{T}$ & Beta & Std. error & $\boldsymbol{B}$ & Dimensions of resilience \\
\hline 0.381 & 1.729 & - & 0.294 & 0.442 & Constant \\
0.000 & 5.413 & 0.262 & 0.031 & 0.289 & Social resilience \\
0.000 & 4.007 & 0.186 & 0.087 & 0.182 & Institutional resilience \\
0.006 & 2.972 & 0.169 & 0.025 & 0.159 & Physical resilience \\
0.013 & 2.361 & 0.153 & 0.036 & 0.078 & Environmental resilience \\
0.000 & 2.118 & 0.138 & 0.038 & 0.047 & Infrastructural resilience \\
0.011 & 2.008 & 0.112 & 0.049 & 0.091 & Economic resilience \\
\hline$R=0.711, R^{2}=0.428$, Adjusted $R^{2}=0.422, F=78.003$, Sig $=0.000$
\end{tabular}

the case study. These interviews had an average length of $40 \mathrm{~min}$. Dimensions and characters of assessing resilience in Region 8 of Tehran were extracted according to the previous studies and based on cultural and social conditions of this region (Table 4).

These indicators were shown in questionnaires in a 5-unit Likert spectrum from very low to very high (very low, low, medium, high, very high) and the answers were analyzed via "Exploratory factor analysis" and SPSS software. Result of the analysis of dimensions of resilience in Region 8 of Tehran is shown in Table 5.

\subsubsection{Reliability coefficient}

The survey comprised six scales totaling 28 items. Alpha is a coefficient of reliability which measures test or item battery reliability based on its internal consistency. The Alpha coefficients all exceed 0.8, indicating that the variables have acceptable reliability.

\section{Findings}

According to the regression analysis (Table 6), the adjusted $R^{2}$ is 0.422 ; thus, $42 \%$ of resilience changes of Region 8 of Tehran relate to the six factors, which are social condition, economic condition, physical condition, environmental condition, urban infrastructure, and institutional capacity. Thus, the other $58 \%$ of resilience changes relate to the factors that are not mentioned in this paper. As it is shown in Table 4, there is a direct positive relationship between social condition and resiliency $(0.262 \%)$ (social resilience), and social
Table 6. Priority of resilience in different urban dimensions in Region 8 of Tehran as the case study (source: Statistical analysis).

\begin{tabular}{cl}
\hline Priority & Dimension \\
\hline 1 & Social resilience \\
2 & Institutional resilience \\
3 & Physical resilience \\
4 & Environmental resilience \\
5 & Infrastructural resilience \\
6 & Economic resilience \\
\hline
\end{tabular}

condition has the most important role in forecasting changes of resilience in Region 8 of Tehran. There is a direct positive relationship between economic condition and resiliency, $(0.112 \%)$ (economic resilience), there is a direct positive relationship between physical condition and resiliency $(0.169 \%)$ (physical resilience), there is a direct positive relationship between environmental condition and resiliency (0.153) (environmental resilience), there is a direct positive relationship between urban infrastructure and resiliency $(0.138 \%)$ (infrastructural resilience), and there is a direct positive relationship between institutional capacity and resilience $(0.186 \%)$ (institutional resilience). Thus, all hypotheses of this paper are proved. As it is mentioned above, the highest resilience relates to social resilience and the lowest relates to economic resilience. In Table 5 , the priority of resilience in Region 8 of Tehran is shown.

Based on the 5-unit Likert spectrum, the whole 


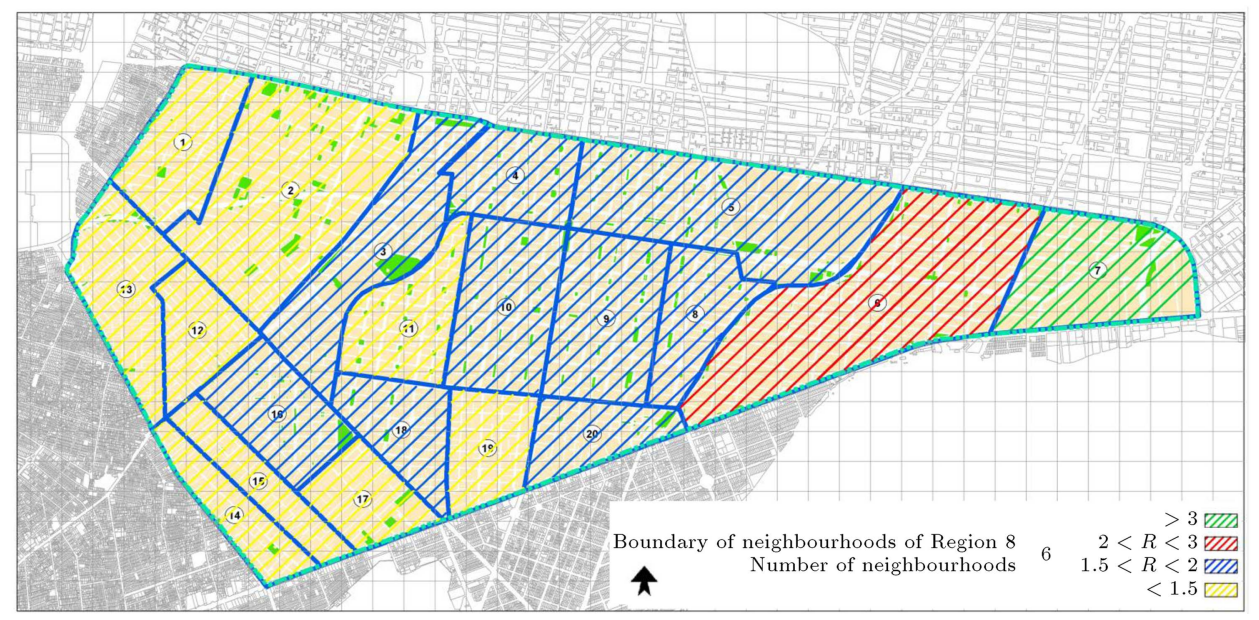

Figure 4. Average of resilience in the neighborhood of Region 8 of Tehran ( $R$ " is the abbreviation of Resilience).

average of resilience can be " 1 to 5 ". Number " 1 " is the lowest resiliency, " 5 " is the highest (ideal resiliency), and " 3 " is the middle. After analyzing questionnaires via statistical analysis, the average rank of urban resiliency in the case study was 2.6 , which shows Region 8 is in a low position in case of urban resiliency.

In Figure 4, the average of resilience in different neighborhoods of Region 8 of Tehran is shown. As shown in Figure 4, the rank of resilience in neighborhood 7 at the east of Region 8 is the highest (> 3) and the lowest rank of resilience relates to the neighborhoods which are at the west of Region 8 $(<1.5)$.

\section{Conclusion}

By conceptualizing cities as complex adaptive systems and reducing cities into components and analytical elements, we are better able to work towards resiliency enhancements. People, activities, institutions, resources, and processes interact in emergent patterns that create the dynamic, unknowable ordering that is a resilient city. Transition to a resilient urban society draws upon numerous factors and there are many cultural and site-specific parameters that may impede broad spectrum prescriptions. In this paper, the cultural and socio-economic attributes of Tehran City have been taken into account for assessing resilience in the case study. The average rank of urban resiliency was 2.6, which shows Region 8 is in a low position in case of urban resiliency. The highest resilience in Region 8 of Tehran relates to social resilience and the lowest relates to economic resilience. The research findings can be used by policy-makers and planners. Testing the proposed model of this paper provides a basis for future studies to systematically examine the significant factors affecting resiliency. This has important implications for policy. More research is needed in this context and the present study provides a platform for the research on the resilient city.

\section{References}

1. Lawrence, R.J. "Housing and health: From interdisciplinary principles to trans disciplinary research and practice", Futures, 36(4), pp. 487-502 (2004).

2. White, I. "Risk, resilience and spatial planning", Routledge, Oxon (2010).

3. Mileti, D., Disasters by Design, Josef Henry Press, Washington, Dc (1999).

4. Davoudi, S. "Resilience: A bridging concept or a dead end?", Planning Theory \& Practice, 13(2), pp. 299-333 (2012).

5. Desouza, Kevin C. and Flanery, T.H. "Designing, planning, and managing resilient cities: A conceptual framework", Cities, 35, pp. 89-99 (2013).

6. Birkmann, J., Indicators and Criteria, in Measuring Vulnerability to Natural Hazards: Towards Disaster Resilient Societies, edited by J. Birkmann, United Nations University Press, Tokyo (2006).

7. Peiwen, Lu "Understanding the notion of resilience in spatial planning: A case study of Rotterdam, The Netherlands", Cities, 35, pp. 200- 212 (2013).

8. Naveh, Z. "What is holistic landscape ecology? A conceptual introduction", Landscape and Urban Planning, 50, pp. 7-26 (2000).

9. Collier, M.J., Nedovic-Budic, Z., Aerts, J. et al. "Transitioning to resilience and sustainability in urban communities", Cities, 32, pp. 21-28 (2013).

10. UNISDR “Advocacy for urban resilience: UNISDR's making cities resilient campaign", Environment and Urbanization, 26, pp. 74-78 (2014).

11. Jabareen, Y. "Planning the resilient city: Concepts and strategies for coping with climate change and environmental risk", Cities, 31, pp. 220-229 (2013).

12. Cutter, S.L., Barnes, L., Berry, M. et al., Community and Regional Resilience: Perspectives from Hazards, 
Disasters, and Emergency Management, CARRI Research Report1 (2008).

13. Holling, C.S. "Resilience and stability of ecological systems", Annual Review of Ecology and Systematics, 4, pp. 1-23 (1973).

14. Adger, W.N. "Social and ecological resilience: Are they related", Progress in Human Geography, 24(3), pp. 347-364 (2000).

15. Klein, R.J.T., Nicholls, R.J. and Thomalla, F. "Resilience to natural hazard: How useful is this concept", Environmental Hazards, 5, pp. 35-45 (2003).

16. Alberti, M., Marzluff, J.M., Shulenberger, E., Gordon, B., Ryan, C. and Zumbrunnen, C. "Integrating humans into ecology: Opportunities and challenges for studying urban ecosystems", Bioscience, 53(12), pp. 1169-1179 (2003).

17. Bruneau, M., Chang, S.E., Eguchi, R.T. et al. "A framework to quantitatively assess and enhance the seismic resilience of communities", Earthquake Spectra, 19(4), pp. 733-752 (2003).

18. Adger, W.N. Vulnerability, Global Environmental Change, 16(3), pp. 268-281 (2006).

19. Ernstson, H., van der Leeuw, S.E., Redman, C.L., Meffert, D.J., Davis, G., Alfsen, C. and Elmqvist, T. "Urban transitions: On urban resilience and humandominated ecosystems", AMBIO: A Journal of the Human Environment, 39(8), pp. 532-545 (2010).

20. UNISDR, "International strategy for disaster reduction, making cities resilient: My city is getting ready", 2010-2011. World Disaster Reduction Campaign (2010).

21. Godschalk, D.R. "Urban hazard mitigation: Creating resilient cities", Natural Hazards Review, 4(3), pp. 136143 (2003).

22. Walker, B. and Salt, D. Resilience Thinking: Sustaining Ecosystems and People in a Changing World, Island Press, Washington, DC (2006).

23. Fleischhauer, M. "The role of spatial planning in strengthening urban resilience", In H.J. Pasman \& A. I. A.K. (Eds.), Resilience of Cities to Terrorist and other Threats, pp. 273-297, Springer (2008).

24. Hutter, G. "Planning for risk reduction and organizing for resilience in the context of natural hazard", German Annual of Spatial Research and Policy (2010).

\section{Appendix}

List of the questions in questionnaire:

1. How is the social capital in Region 8 of Tehran?

2. How is the sense of belonging in Region 8 of Tehran?

3. Do citizens of Region 8 participate in urban activities?
4. How is the rate of immigration in the Region 8 of Tehran?

5. Is the population in Region 8 of Tehran equally distributed?

6. Can people freely engage in worship?

7. Do you think the income of people in this region is more than their costs?

8. Is there a good rate of employment in this region?

9. How many percent of people are owner of dwelling?

10. Do you think people are satisfied with economic stability?

11. Is this region sustainable in environmental context?

12. Are the geographic features in a way that makes life easier for people?

13. Is there a good belonging of natural resources in Tehran with special reference to Region 8 ?

14. Commercial per capita in Region 8 of Tehran is sufficient.

15. Residential per capita in Region 8 of Tehran is sufficient.

16. Industrial per capita in Region 8 of Tehran is sufficient.

17. Educational per capita in Region 8 of Tehran is sufficient.

18. Region 8 of Tehran has a good form in the context of city form.

19. Historic places are well maintained.

20. Essential urban infrastructure such as water is sufficient.

21. Essential urban infrastructure such as electricity is sufficient.

22. Essential urban infrastructure such as gas is sufficient.

23. Transportation system in Region 8 of Tehran is safe, rapid, cheap, well maintained and equally distributed.

24. People in Region 8 can use internet easily.

25. Urban management has a significant role in the achievement of resiliency.

26. Regulations and standards help to achieve resiliency.

27. Maneuver and education about hazards (such as earthquake) are continuously and timely held.

28. What is your idea about the rank of each neigh- 
borhood of Region 8 of Tehran in resiliency (from 1 "the lowest" to 5 "the highest")?

\section{Biographies}

Manouchehr Tabibian, Emeritus Professor of University of Tehran, has received MA in Architecture from University of Tehran, in 1966, PhD in Planning from University of Tehran, in 1974, and MS in Regional Science from University of Pennsylvania, USA, in 1978. His interest is teaching to $\mathrm{PhD}$ and graduate students of Urban Planning, Architecture, and Urban Design. He has been doing this job over the last 40 years. Now, he is Head of the Department of City Planning and Urban Design in the School of Architecture and City Planning at the Islamic Azad University of Qazvin. He has published and written over 15 books and more than
40 articles. Recently, he has been selected as Editorin-Chief of The Space Ontology Journal by the Azad University of Qazvin.

Maryam Rezapour has been PhD student of Urban Planning and Design in the Faculty of Architecture at the Islamic Azad University of Qazvin, Qazvin, Iran, since 2013. She received MS in Urban and Regional Planning in the Faculty of Architecture and Urban Planning at Shahid Beheshti University, Tehran, Iran, in 2010. She has been a lecturer in Urban Planning Department at Karaj Payame Noor University since 2010. She has worked as a planning consultant in some of the projects in Tehran city. Her interest is teaching to Urban Planning and Architecture Students. She has cooperated in writing 2 books and more than 8 articles. 